\section{Medical Waste Position Paper}

The SHEA Position Paper on Medical Waste, authored by Drs. William Rutala and C. Glen Mayhall, will be published in the January issue of the journal. Dr. Mayhall has released preprints of the position paper to the American Hospital Association and to the American Medical Association. They will be using this material to help educate members of Congress about the factual scientific issues of medical waste.

\section{Hospital Epidcmiology Training Course}

Plans are underway to present the highly successful SHEA-CDCAHA training course twice during the fall of 1992. The specific dates and sites are now being finalized. Look for the course announce ments in upcoming issues of the journal.

\section{NIH Training Program in Hospital Epidemiology}

The National Institutes of Health (NIH) has awarded a five-year training grant for hospital epidemiology to The University of Iowa, Iowa City, Iowa. Interested candidates who have completed residency training in internal medicine, pediatrics, or general surgery should call or send inquiries to Richard P. Wenzel, MD, MSc, Professor and Director, Division of General Medicine, Clinical Epidemiology, and Health Services Research, The University of Iowa College of Medicine, Iowa City, IA 52242. Telephone (319) 3561838 .

\section{SHEA Annual Luncheon Speaker}

Debra Nadzam, PhD, RN, Project Manager, Indicator Development, Joint Commission on Accreditation of Healthcare Organizations (JCAHO), was the featured speaker at the October 1, 1991, luncheon. Her talk on the current status of infection control indictor

\begin{abstract}
development was exceptionally well received by the standing-roomonly crowd. To benefit those who could not attend, Dr. Nadzam has graciously agreed to prepare a manuscript of her talk, which will appear in the SHEA Newsletter.
\end{abstract}

Brief items of interest for the SHEA N ews or N ewsletter may be sent to Robert A. W einstein, M D, SHEA, N ewsletter Editor, Division of Infectious D iseases, M ichael Reese H ospital, Lake Shore D rive at 31st St., Chicago, IL 60616; FAX (312) 791-3577. Copy must be typed, doublespaced, and may not exceed five pages. 